\title{
Point quadrat versus video transect estimates of the cover of benthic red algae
}

\author{
George H. Leonard*, Ross P. Clark \\ Moss Landing Marine Laboratories, PO Box 450, Moss Landing, Californía 95039, USA
}

\begin{abstract}
Point quadrat (PQ) and video transect (VT) techniques were compared to determine the feasibility of using the latter to sample subtidal red algal assemblages. More taxa were found by PQs than by VTs, both overall and on a per quadrat basis. VTs tended to overestimate the percent cover of rock and articulated coralline algae. VTs were incapable of resolving many of the less common red algae. Video sampling required less time in the field than point quadrats but laboratory analysis was very time consuming. Lack of resolution and extensive laboratory analysis make this technique insufficient for sampling benthic red algal populations. However, VTs may be useful in documenting large-scale differences between regions, such as the percent cover of understory kelps or the density of large mobile invertebrates in central California kelp forests. Video sampling has been successfully used in the intertidal but traditional, random point quadrats still appear to be the most efficient and accurate way to sample benthic communities in kelp forests.
\end{abstract}

The advent of quantitative techniques to sample subtidal benthic communities has aided the scientific description of pattern and helped transform marine ecology from a wholly observational to a more experimental science. Techniques to measure percent cover were first developed by terrestrial botanists (e.g. Greig-Smith 1983) and have been successfully adapted to subtidal communities by marine ecologists (e.g. Foster 1975, Cowen et al. 1982, Kennelly 1987).

Photography has been used quantitatively in intertidal, subtidal and deep-sea habitats (Bohnsack 1979, Budd 1982, Witman \& Sebens 1985, Jaap 1986, Rosman \& Boland 1986, Thouzeau \& Hily 1986, Meulstee et al. 1988, Edmunds \& Witman 1991). Due to recent advances in video resolution and ease of use, it has begun to replace traditional photography as both a qualitative (Potts et al. 1987, Semple \& Sharp 1988) and quantita-

\footnotetext{
- Present address: Graduate Program in Ecology and Evolutionary Biology, Brown University, Providence, Rhode Island 02912, USA
}

tive (Jaap et al. 1990, Maney et al. 1990, Berklemans 1992) sampling tool. The strength of video is its ability to rapidly acquire data and permit analysis in the laboratory at a later date. Video quadrats and transects are now being used routinely to measure the density and percent cover of subtidal marine organisms (e.g. Edmunds \& Witman 1991).

As part of a study on the effect of light on understory algae in central California (USA) kelp forests, we have been using point quadrats to estimate algal cover. These involve scoring a small number of random points (usually 10 to 20 ) along a bar randomly placed on the substrate. This technique is excellent for relatively abundant organisms but, theoretically, undersamples rare species because of the few points used. Whorff \& Griffing (1992) recently suggested that point quadrats undersample the substrata while Foster et al. (1991) concluded that point quadrats provide better estimates of the total number of taxa and their total and individual percent cover. An alternative to point quadrat methods for rare species are search techniques (e.g. Nybakken 1978, McClanahan 1990, McClanahan \& Muthiga 1992). These have been designed for extremely rare species (i.e. approximately 0.1 ind. $\mathrm{m}^{-2}$; McClanahan \& Muthiga 1992) but understory algae in many benthic habitats range from 1 to $30 \%$ cover (Foster 1975).

In this paper, we present results of a direct comparison of point quadrat (PQ) and video transect (VT) sampling for benthic algal assemblages. Video was used over traditional photo-quadrats because video film is significantly cheaper than still film and more samples can be taken between film changes. To test for and alleviate the potential PQ bias of using too few points, we sampled the video image using 5 times as many random points as the $P Q$. This should have increased the likelihood of detecting rare species. The number of 


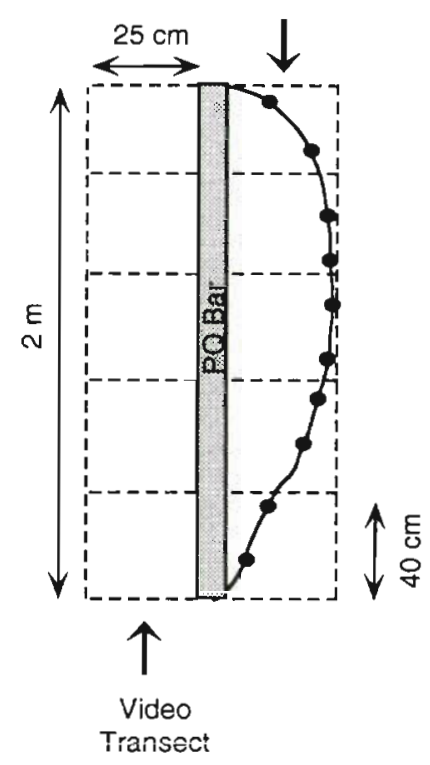

Fig. 1. Diagram of the point quadrat and video transect sampling design

taxa found and their relative percent covers were compared between the 2 methods and a cost-benefit analysis was done to determine the efficiency of using video to sample algal populations. These results are applicable to those considering the use of video to sample algal populations in temperate waters for either shortterm experiments, descriptive studies or long-term monitoring.

Methods. Point quadrats and video transects were done in Stillwater Cove, Carmel Bay, California $\left(36^{\circ}\right.$ $\left.34^{\prime} \mathrm{N}, 121^{\circ} 56^{\prime} \mathrm{W}\right)$ over a 2 d period in March 1992. Data were collected in $10 \mathrm{~m}$ of water with visibility approximately $5 \mathrm{~m}$. Each $\mathrm{PQ}$ consisted of scoring 10 points (knots tied haphazardly in a loose string) along both sides of a $2 \mathrm{~m}$ PVC bar (20 points total; Fig. 1). Each point represented $5 \%$ cover. Direct comparisons with PQs were made by filming a video transect of the same region sampled by the $P Q$ bar. This area was approximately $1 \mathrm{~m}^{2}(4 \mathrm{~m} \times 0.25 \mathrm{~m}$; Fig. 1). Video was taken using a Sony CCD-V99 high band $8 \mathrm{~mm}$ camera equipped with a $46 \mathrm{~mm} 0.5 \times$ video wide-magnification lens operating at a shutter speed of $1 / 60 \mathrm{~s}$. The camera housing was manufactured by AquaVideo and was equipped with an Ikelite dome port. Transects were filmed $0.5 \mathrm{~m}$ above the bottom and this distance was held constant with a fixed-length positioning bar. Speed over the bottom was approximately $4 \mathrm{~m} \mathrm{~min}^{-1}$. Two sets of data were collected within a multi-layered algal habitat within Stillwater Cove. The first consisted of 5 replicates of PQs and VTs shot with natural light. The second consisted of 8 replicates of PQs and VTs shot using 2 underwater video lights ('artificial light').
These lights did not create 'hot spots'. Color balance was adequate as evidenced by the natural appearance of invertebrates and coralline algae. Each replicate was a haphazardly located PQ/VT pair

VT data were analyzed in the laboratory using a Mitsubishi HS-U54 video cassette recorder which allowed frame-by-frame analysis and a Sony PVM1343MD color monitor. Each transect was subdivided into 10 smaller, contiguous quadrats measuring approximately $25 \times 40 \mathrm{~cm}$ (Fig. 1). Ten random points from each of the smaller quadrats were enumerated for species of red and brown algae as well as substrate type if no algae were present (100 points total). Each individual point sampled represented $1 \%$ cover. The time to analyze each VT was also recorded. Algae were identified as in Abbott \& Hollenberg (1976).

The number of different cover types (henceforth referred to as 'taxa') observed with each technique was compared by using a 2-tailed, paired t-test. PQs were considered the standard against which the accuracy of VTs were compared. Further, the relative abundances of 4 of these taxa (Rock, Corallines, Plocamium cartilageneum and All Others) were compared using a
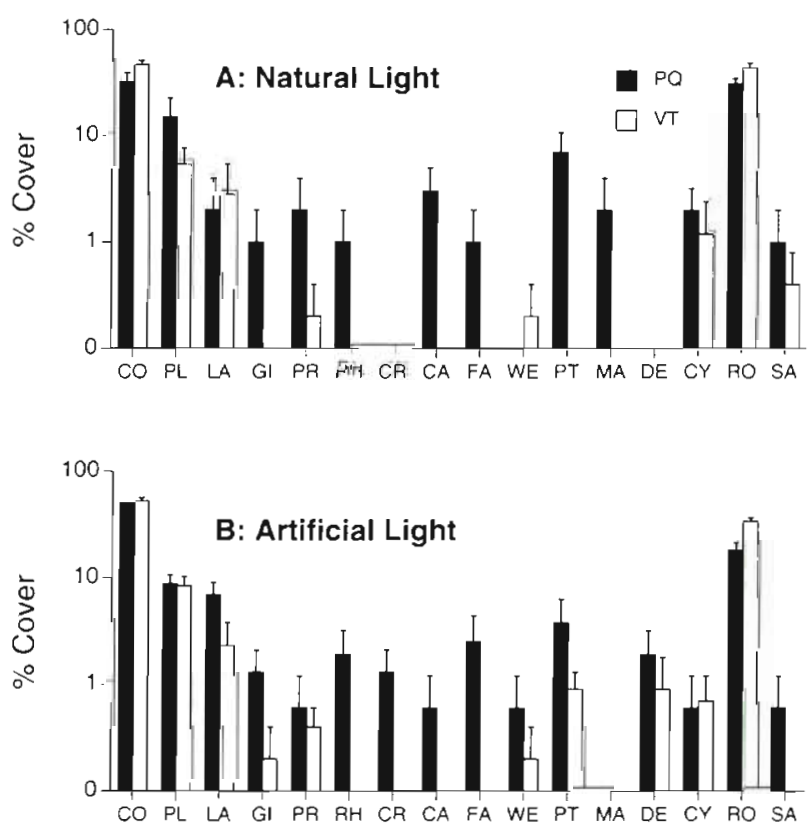

Fig. 2. Comparison of percent cover (mean $\pm 1 \mathrm{SE}$ ) of red and brown algae, rock and sand sampled by point quadrat (PQ) and video transect (VT). Scale is logarithmic to emphasize small values of percent cover for the red algae. (A) Natural light, $\mathrm{n}=5$. (B) Artificial light, $\mathrm{n}=8 . \mathrm{CO}=$ articulated coralline algae; $\mathrm{PL}=$ Plocamium cartilagineum $\mathrm{LA}=$ Laurencia sub . boposita; $\mathrm{GI}=$ Gigartina corymbifera; $\mathrm{PR}=$ Prionitis lanceolata; $\mathrm{RH}=$ Rhodymenia spp.; $\mathrm{CR}=$ Cryptopleura farlowanium; $\mathrm{CA}=$ Callophyllis spp.; FA = Fauchea spp.; WE = Weeksia spp.; PT = Pterygophora californica $; \mathrm{MA}=$ Macrocystis pyrifera $;$ DE $=$ Desmarestia spp $; \mathrm{CY}=$ Cystoseira osmundacea $\mathrm{RO}=$ bare rock; $\mathrm{SA}=$ sand 
heterogeneity chi-square analysis (Zar 1976). The time to analyze each VT was used to conduct a cost-benefit analysis based on a total sample size of 180 quadrats. This analysis was calculated on both a 'total days' and 'work hours' basis and time was considered to be the only cost (see 'Discussion'). 'Total days' refers to the total number of days needed to collect and analyze the data, regardless of the number of workers. 'Work hours', which incorporated the number of workers, is the total number of hours worked while acquiring and analyzing the data.

Results. A combined total of 16 taxa was found using both PQ and VT techniques either with natural or artificial light (Fig. 2). Consistently more taxa were found using PQs than VTs (2-tailed, paired $t$-test: mean difference $=1.308, \mathrm{df}=12, t=3.77, \mathrm{p}=0.0027$ ) .

Thirteen taxa were found by PQs while only 8 were found by natural light VTs (Fig, 2a). The 6 taxa found by PQ but not VT were Gigartina corymbifera, Rhodymenia spp., Callophyllis spp., Fauchea spp., Pterygophora californica and Macrocystis pyrifera. Weeksia spp. was detected by VT but not PQ. Two taxa, Cryptopleura farlowanium and Desmarestia spp., were not present. Natural light VTs detected $57.1 \%(8$ of 14) and PQs detected $92.9 \%$ (13 of 14) of the total taxa found by both methods. Rock, corallines and Plocamium cartilagineum had the highest percent cover using either technique. Heterogeneity chisquare analysis did not allow for pooling of the replicates and comparison of the distributional pattern of the various taxa (Heter. $\chi^{2}=146.7, \mathrm{df}=12, \mathrm{p}>0.05$ ) However, it appeared that the VTs resulted in a higher percent cover of rock and corallines and a lower percent cover of $P$. cartilagineum than did the PQs.

Fifteen taxa were found by PQs while only 10 taxa were detected with the artificial light VTs (Fig, 2b). The 5 taxa found by PQ but not VT were Rhodymenia spp., Cryptopleura farlowianium, Callophyllis spp., Fauchea spp. and sand. No taxa were detected by VT and missed by PQ. One taxon, Macrocystis pyrifera, was not present. Artificial light VTs detected $66.7 \%$ (10 of 15) and PQs detected 100\% (15 of 15) of the total taxa found by both methods. Sand, rock, corallines and Plocamium cartilagineum again had the highest percent cover regardless of the technique. As in the natural light samples, heterogeneity chi-square analysis did not allow for pooling of the 8 replicates (Heter. $\chi^{2}=$ $32.3, \mathrm{df}=21, \mathrm{p}=0.05$ ). VTs, rather than PQs, seemed to have a higher percent cover of rock but a similar percent cover of corallines and $P$. cartilagineum.

The cost-benefit analysis suggested that, on a 'total days' basis, point quadrats were more cost effective than video transects (Table 1). Four divers would need $4 \mathrm{~d}$ to sample 180 PQs (at 45 quadrats $\mathrm{d}^{-1}$ ) in Stillwater

Table 1. Cost-benefit analysis. 'Total days' is the number of days needed to collect and analyze the percent cover data regardless of the number of workers. 'Work hours' is the total number of worker hours needed to acquire and analyze the data. This is a function of the number of divers working in the field as well as transport to and from the study site. Unlike PQs, VTs require extensive laboratory analysis

\begin{tabular}{|c|c|c|c|c|c|}
\hline \multicolumn{3}{|c|}{ Total days basis } & \multicolumn{3}{|c|}{ Work hours basis } \\
\hline \multicolumn{6}{|c|}{ Point quadrats } \\
\hline \multirow[t]{6}{*}{ Sampling } & (A) No. of quadrats & 180 & \multirow[t]{6}{*}{ Sampling } & (A) No. of quadrats & 180 \\
\hline & (B) Quadrats sampled $\mathrm{d}^{-1}$ & 45 & & (B) Quadrats sampled $d^{-1}$ & 45 \\
\hline & (C) Total days $(A / B)$ & 4 & & (C) No of days $(A / B)$ & 4 \\
\hline & & & & (D) No. of divers $\mathrm{d}^{-1}$ & 4 \\
\hline & & & & (E) No. hours $\mathrm{d}^{-1}$ & 8 \\
\hline & & & & (F) Work hours $(C \times D \times E)$ & 128 \\
\hline \multicolumn{6}{|c|}{ Video transects } \\
\hline \multirow[t]{4}{*}{ Sampling } & (A) No. of quadrats & 180 & \multirow[t]{4}{*}{ Sampling } & (A) No. of quadrats & 180 \\
\hline & (B) Quadrats sampled $d^{-1}$ & 90 & & (B) Quadrats sampled $d^{-1}$ & 90 \\
\hline & (C) No. of days $(A / B)$ & 2 & & (C) No. of days (A/B) & 2 \\
\hline & & & & (D) No. of divers $\mathrm{d}^{-1}$ & 2 \\
\hline \multirow[t]{6}{*}{ Analysis } & (D) Time quadrat ${ }^{-1}$ (min) & 11.5 & & (E) No. of hours $\mathrm{d}^{-1}$ & 8 \\
\hline & (E) Total hours $(A \times D / 60)$ & 34.5 & \multirow{5}{*}{ Analysis } & (F) Work hours $(\mathrm{C} \times \mathrm{D} \times \mathrm{E})$ & 32 \\
\hline & (F) Maximum lab period $\left(\mathrm{h} \mathrm{d}^{-1}\right)$ & 7 & & & \\
\hline & (G) Total lab time (d) (E/F) & 5 & & (G) Time quadrat ${ }^{-1}(\mathrm{~min})$ & 11.5 \\
\hline & \multirow[t]{2}{*}{$(\mathrm{H})$ Total days $(\mathrm{C}+\mathrm{G})$} & \multirow[t]{2}{*}{7} & & (H) Lab work hours $(\mathrm{A} \times \mathrm{G} / 60)$ & 34.5 \\
\hline & & & & (I) Total work hours $(F+H)$ & 66.5 \\
\hline \multicolumn{6}{|c|}{ Summary } \\
\hline \multirow[t]{2}{*}{ Total days } & Point quadrats & 4 & \multirow[t]{2}{*}{ Work hours } & Point quadrats & 128.0 \\
\hline & Video transects & 7 & & Video transects & 66.5 \\
\hline
\end{tabular}




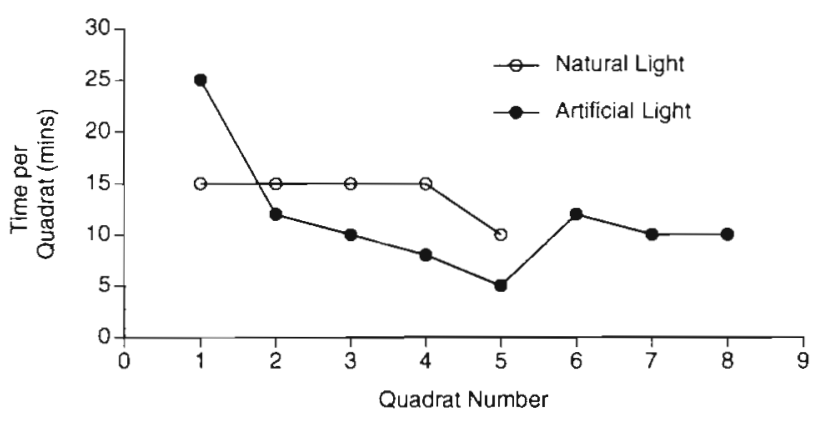

Fig. 3. Time required to analyze video quadrats. Downward slope of curves indicates increased proficiency as more quadrats were analyzed. Mean time to analyze artificial light quadrats was $11.5 \mathrm{~min}$

Cove. At this time, data would be 'in hand' and ready for entry into a database. In contrast, only $2 \mathrm{~d}$ are needed to film 180 VTs (at 90 quadrats $\mathrm{d}^{-1}$ ).

The time to analyze a single VT in the laboratory ranged from 10 to $15 \mathrm{~min}$ for the natural light samples and from 5 to $25 \mathrm{~min}$ for the artificial light samples (Fig. 3). Time decreased as observers gained experience analyzing the video. The mean time for an artificial light VT replicate was $11.5 \mathrm{~min}$. Using this value, analysis of 180 quadrats would require nearly $35 \mathrm{~h}$ of video computer analysis alone. A maximum of $7 \mathrm{~h} \mathrm{~d} \mathrm{~d}^{-\mathrm{t}}$ could be spent in the lab. This indicates that nearly $5 \mathrm{~d}$ are needed to analyze the VTs once they have been shot. This results in a total sampling time of $7 \mathrm{~d}$ for VTs versus $4 \mathrm{~d}$ for PQs.

On a 'work hour' basis, PQs were found to be much less cost effective than VTs (Table 1). PQs required nearly twice as many work hours as did VTs. Four divers would need $4 \mathrm{~d}$ to sample 180 PQs. As each day corresponds to $8 \mathrm{~h}$ of work (of which only $3 \mathrm{~h}$ are spent underwater) this represents 128 work hours. In contrast, 2 divers could sample all 180 VTs in $2 \mathrm{~d}$ of field work. At the same $8 \mathrm{~h} \mathrm{~d}^{-1}$, this represents 32 work hours. As in the 'total days' analysis, 35 work hours would be required for laboratory analysis. In total, VTs would require only 67 work hours while PQs would require 128 .

Discussion. Table 2 summarizes the advantages and disadvantages of video sampling. In this study, video transects were less accurate than point quadrats to sample benthic red algae in subtidal kelp forests. These results are similar to those of Foster et al. (1991) who found that point quadrats detected more taxa than did photo-quadrats in intertidal communities. On an average per quadrat basis, PQs detected 1.3 more taxa than did VTs in our study. Overall, PQs detected 5 more taxa than did VTs shot under either natural or artificial lighting. Nearly all these extra taxa were species of red algae including Gigartina corymbifera,
Rhodymenia spp., Cryptopleura farlowianium, Callophyllis spp. and Fauchea spp.

It was clear from both casual observations and the data analysis that video was incapable of detecting the smaller species of red algae. Maney et al. (1990) had similar difficulties distinguishing organisms of less than $1 \mathrm{~cm}$ filmed in a field of view of $1 \mathrm{~m}^{2}$ while Whorff \& Griffing (1992) overcame this limitation by filming very small, $36 \mathrm{~cm}^{2}$ quadrats. Although resolution may have been enhanced by filming closer to the substrate, the spatial scale of these observations would not have been appropriate for the organisms in this habitat.

The inability to detect some species was likely due to the resolution of one or many of the following: the camera and lights, the tape, the video player, or the monitor. Our results suggest that underwater lights slightly increased the camera's detection limits. With lights, $66.7 \%$ of the taxa were detected while, without lights, this number was $57.1 \%$. However, even with artificial lighting, the algae appeared quite dark on the video. This was probably due to the high concentration of light absorbing photosynthetic pigments. This was not a result of poor color balance because invertebrates appeared natural on the film. It is expected that even brighter lights would not ameliorate this problem. Similar difficulties occur even under high intensity flash photography (R. Clark pers. obs.).

Video was reasonably successful at sampling the most abundant taxa such as rock, corallines and Plocamium cartilagineum. Even so, rock and corallines may have been overestimated using VTs because an item that could not be identified or that was simply not seen, often was scored as one of these 2 categories.

An additional benefit of PQs not available with VTs is that PQs can provide information on algal layering. A point on a $P Q$ can have multiple layers of organisms above and below it (e.g. rock, coralline, Plocamium

Table 2. Summary of disadvantages and advantages of video sampling

\begin{tabular}{|c|c|}
\hline Disadvantages & Advantages \\
\hline $\begin{array}{l}\text { (1) Lack of resolution } \\
\text { (2) Extensive lab analysis } \\
\text { (3) Inability to sample } \\
\text { layers }\end{array}$ & $\begin{array}{l}\text { (1) Rapid data acquisition } \\
\text { (2) Cost effective when } \\
\text { diver time is expensive } \\
\text { (3) Provides permanent } \\
\text { record } \\
\text { (4) Qualitative site overview } \\
\text { or quantitative sampling } \\
\text { of large organisms } \\
\text { (5) Maximizes data } \\
\text { acquisition with limited } \\
\text { dive time }\end{array}$ \\
\hline
\end{tabular}


cartilagineum, Pterygophora californica and Macrocystis pyrifera) while a point on a VT can only have a single organism under it. Much of the detail concerning the contribution of algal layers to overall percent cover is lost using VTs, a drawback also observed by Jaap (1986). Meese \& Tomich (1992) also could not sample layers when digitizing images of intertidal quadrats. This problem can be overcome with intertidal photo-quadrats (or video images) by moving aside successive layers. This is nearly impossible in subtidal environments where strong surge is common.

In addition to not detecting some species, video was alsa time consuming on a 'total days' basis (Table 1). Cost-benefit analysis showed that 3 more days were required to obtain and analyze video data than were required for $P Q$ data. The added time spent in the field to collect PQ data (4 vs 2 d) was offset by the additional time required for laboratory analysis of VTs. Whorff \& Griffing (1992) also noted that laboratory analysis of video can take from $1 \mathrm{~min}$ to over $2 \mathrm{~h}$ per quadrat.

The results of the 'work hours' cost-benefit analysis were strikingly different from those of the 'total days' analysis and suggested that video was very cost effecient when one considers the total number of workers involved. In this case, the time to collect $P Q$ data is nearly 2 times greater than that for VTs. This is because fewer people can collect the same amount of data in less time using video. Video is therefore a very cost efficient sampling device when numerous divers are unavailable or their time is expensive. These conditions often exist at remote sampling sites. On the other hand, PQs are more cost efficient when divers are readily available or their time is inexpensive (e.g. they are working as volunteers).

The cost-benefit analysis did not incorporate capital costs but doing so would not alter its conclusions. Both techniques require access to dive gear and boats. If the cost of the sampling gear is included (VTs - very expensive; PQs - very inexpensive), this only strengthens the conclusion that VTs are less cost effective than PQs on a total days basis. However, on a work hours basis, $P Q s$ may still be more cost effective if labor costs are relatively low. If high, the added cost of video equipment may be offset by the fewer number of hours needed to acquire the VT data. However, each technique's cost effectiveness must always be compared with its ability to detect the organisms of interest.

Video images were not digitally analyzed as in Whorff \& Griffing (1992) and Meese \& Tomich (1992) but were analyzed with random points as in traditional photo-quadrat analysis. Digitizing would be expected to take even longer than random points (e.g. $2 \mathrm{~h}$ quadrat ${ }^{-1}$, Whorff \& Griffing 1992). It would also not overcome the video's inability to distinguish some of the species of red algae. For these reasons, digitization of the video images would not likely have altered our results

Several advantages of video are not evident from this cost-benefit analysis. Video tapes are a permanent record and can be referred to at a later time if data are lost or tapes can be entirely reanalyzed if needed. Video can also often be used under adverse conditions where physical contact with the substrate is difficult or dangerous. Rapid data acquisition by video is also advantageous when dive times become limited by depth (e.g. Witman \& Sebens 1992). Rapid acquisition can also be important in intertidal habitats where time between high tides is short.

Although not formally examined, video transects appeared quite capable of documenting large-scale differences between regions, such as the percent cover of stipitate kelps or the density of large, mobile invertebrates. Berkelmans (1992) concluded that identification to broad category is easily accomplished with video but that its reliability as a species-specific sampling tool is still untested. Our work suggests that lack of resolution is the limiting factor in future use of video technology to analyze benthic red algal assemblages. Close examination with the naked eye is often the only way to detect and indentify these macrophytes.

Acknowledgements. Access to Stillwater Cove was made possible by the Pebble Beach Corporation. W. Broenkow, J. Heine, N. Crane and J. Nybakken kindly provided access to the video equipment. We also thank $J$. Heine for assistance in the field and L. Honma for assistance in the laboratory. G. Cailliet, M. Foster, C. Harrold and 2 anonymous reviewers provided useful comments on earlier drafts of the manuscript

\section{LITERATURE CITED}

Abbott, I. A., Hollenberg, G. J. (1976). Marine algae of California. Stanford University Press, Stanford

Berkelmans, R. (1992). Video photography: a quantitative sampling method. Reef Res. 2: 10-11

Bohnsack, J. A. (1979). Photographic quantitative sampling of hard-bottom benthic communities. Bull. mar. Sci. 29 $242-252$

Budd, J. T. C. (1982). Remote sensing techniques for monitoring salt marsh vegetation in the Solent, southern England. Brit. Phycol. J. 17: 230

Cowen, R. K., Agegian, C. R., Foster, M. S. (1982). The maintenance of community structure in a central California giant kelp forest. J. exp. mar. Biol. Ecol. 64: 189-201

Edmunds, P. J., Witman, J D. (1991). Effect of Hurricane Hugo on the primary framework of a reef along the south shore of St. John, US Virgin Islands. Mar. Ecol. Prog. Ser 78: 201-204

Foster, M. S. (1975). Algal succession in a Macrocystis pyrifera forest. Mar. Biol. 32: 313-329

Foster, M. S., Harrold, C., Hardin, D. D. (1991). Point vs photo quadrat estimates of the cover of sessile marine organisms. J. exp. mar. Biol. Ecol. 146: 193-203

Greig-Smith, P. (1983). Quantitative plant ecology. University of California Press, Berkeley 
Jaap, W. C. (1986). A photogrametric apparatus for rapid areal benthic surveys. In: Mitchell, C. T. (ed.) Diving for science. Proceedings of the sixth annual scientific diving symposium, Oct 31-Nov 3, 1986. American Academy of Underwater Sciences, Costa Mesa, CA, p. 227-231

Jaap, W. C., Wheaton, J. L., Donnelly, K. B. (1990). Materials and methods to establish multipurpose, sustained, ecological research stations on coral reefs at Dry Tortugas. In: Jaap, W. C. (ed.) Diving for science. Proceedings of the tenth annual scientific diving symposium, Oct 4-7,1990. American Academy of Underwater Sciences, Costa Mesa CA, p. 193-203

Kennelly, S. J. (1987). Inhibition of kelp recruitment by turfing algae and consequences for an Australian kelp community. J. exp. mar. Biol. Ecol. 112: 49-60

Maney, E. J., Ayers, J., Sebens, K. P., Witman, J. D. (1990). Quantitative techniques for underwater video photography. In: Jaap, W. C. (ed.) Diving for science. Proceedings of the tenth annual scientific diving symposium, Oct $4-7$, 1990. American Academy of Underwater Sciences, Costa Mesa, CA, p. 255-265

McClanahan, T. R. (1990). Kenyan coral reef-associated gastropod assemblages: distribution and diversity patterns. Coral Reefs 9: 63-74

McClanahan, T. R., Muthiga, N. A. (1992). Comparative sampling methods for subtidal epibenthic gastropods. J. exp. mar. Biol. Ecol. 164: 87-101

Meese, R. J., Tomich, P. A. (1992). Dots on the rocks: a comparison of percent cover estimation methods. J. exp. mar. Biol. Ecol. 165: 59-73

Meulstee, C., Nienhuis, P. H., Van Stokkom, H. T. C. (1988). Aerial photography for biomass assessment in the intertidal zone. Int. J. Remote Sensing 9: 1859-1867

Nybakken, J. (1978). Abundance, diversity and temporal variation in a California intertidal nudibranch assemblage.

This note was submitted to the editor
Mar. Biol. 45: 129-146

Potts, G. W. Wood, J. W., Edwards, J. M. (1987). Scuba diveroperated low-light-level video system for use in underwater research and survey. J. mar. biol. Ass. U.K. 67: 299-306

Rosman, I., Boland, G. S. (1986). Quantitative photography on the Gulf of Mexico continental shelf. In: Oceans ' 86 conference record: science-engineering-adventure, Vol. 1 , Systems, structure and analysis. IEEE Publishing Service, New York, p. 14-18

Semple, R. E., Sharp, G. J. (1988). Seeing is believing: the use of underwater video in fisheries resource management. In: Lang, M. A. (ed.) Diving for science. Proceedings of the eighth annual scientific diving symposium, Sep 29-Oct 2 , 1988. American Academy of Underwater Sciences, Costa Mesa, CA, p. 143-147

Thouzeau, G., Hily C. (1986). A.QUA.R.E.V.E.: une technique nouvelle d'echantillonnage quantitatif de la macrofaune epibenthique des fonds meubles. Oceanologica Acta 9: 509-513

Whorff, J. S., Griffing, L. (1992). A video recording and analysis system used to sample intertidal communities. J. exp. mar. Biol. Ecol. 160: 1-12

Witman, J. D., Sebens, K. P. (1985). Distribution and ecology of sponges at a subtidal rock ledge in the central Gulf of Maine. In: Rutzler, K. (ed.) New perspectives in sponge biology. Third International Conference on the Biology of Sponges, Nov 17-23, 1985, Woods Hole, MA. Smithsonian Institution Press, Washington, DC, p. 391-396

Witman, J. D., Sebens, K. P. (1992), Regional variation in fish predation intensity: a historical perspective in the Gulf of Maine. Oecologia 90: 305-315

Zar, J. H. (1976). Biostatistical analysis. Prentice-Hall, Englewood Cliffs

Manuscript first received: November 25, 1992

Revised version accepted: July 14, 1993 